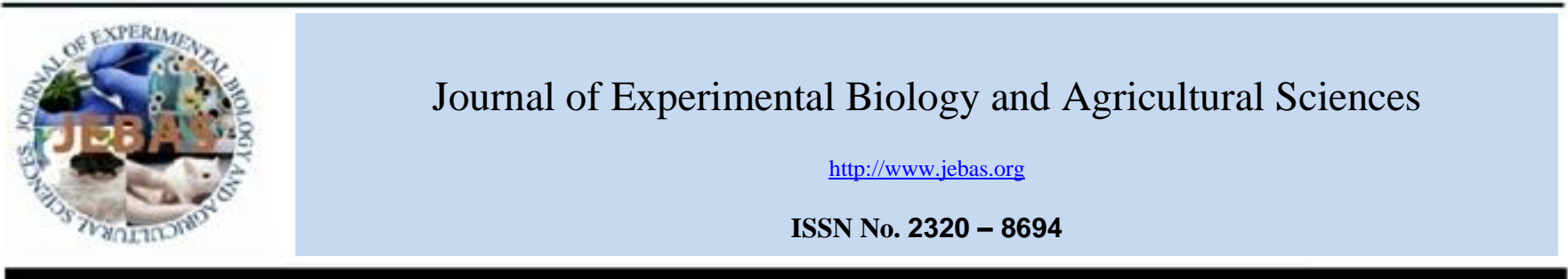

\title{
MYCOPLASMOSIS IN SMALL RUMINANTS IN INDIA: A REVIEW
}

\section{Mohd. Iqbal Yatoo ${ }^{1 *}$, Oveas Rafiq Parray ${ }^{1}$, Masood Salim Mir $^{2}$, Sabiya Qureshi ${ }^{3}$, Zahid Amin Kashoo $^{3}$, Mir Nadeem ${ }^{4}$, Mujeeb Ur Rehman Fazili ${ }^{1}$, Noor Alam Tufani ${ }^{1}$, Maheshwar Singh Kanwar $^{4}$, Sandip Chakraborty ${ }^{5}$, Kuldeep Dhama ${ }^{6}$ and Rajneesh Rana ${ }^{7 *}$}

\footnotetext{
${ }^{1}$ Division of Veterinary Clinical Complex, Faculty of Veterinary Sciences and Animal Husbandry, Shuhama, Srinagar-190006, Jammu and Kashmir, India. ${ }^{2}$ Division of Veterinary Pathology, Faculty of Veterinary Sciences and Animal Husbandry, Shuhama, Srinagar-190006, Jammu and Kashmir, India.

${ }^{3}$ Division of Veterinary Microbiology and Immunology, Faculty of Veterinary Sciences and Animal Husbandry, Shuhama, Srinagar-190006, Jammu and Kashmir, India.

${ }^{4}$ Krishi Vigyan Kendra Nyoma (Changthang), Leh, Jammu and Kashmir-194404, India

${ }^{5}$ Department of Veterinary Microbiology, College of Veterinary Sciences and Animal Husbandry, R.K. Nagar, West Tripura 799008, India.

${ }^{6}$ Division of Pathology, ICAR-Indian Veterinary Research Institute, Izatnagar, Bareilly-243122, Uttar Pradesh, India

${ }^{7}$ Division of Bacteriology and Mycology, ICAR-Indian Veterinary Research Institute, Izatnagar, Bareilly-243122, Uttar Pradesh, India
}

Received - November 25, 2017; Revision - February 17, 2018; Accepted - March 13, 2018

Available Online - April 25, 2018

DOI: http://dx.doi.org/10.18006/2018.6(2).264.281

\section{KEYWORDS \\ Mycoplasmosis \\ Goat \\ Sheep \\ Pathology \\ Diagnosis \\ Vaccine}

\begin{abstract}
Mycoplasmosis, the diseases caused by mycoplasma, are one of the challenging and continuous threats to small ruminant farming. They cause heavy morbidity (upto 100\%), mortality (10-100\%) and huge economic loss. Common diseases caused by mycoplasma organisms are contagious caprine pleuropneumonia (mostly in goats), contagious agalactia (both sheep and goats), atypical pneumonia (usually sheep), besides arthritis, mastitis, seminal vesiculitis, ampullitis, epididymitis, orchitis, urethritis, conjunctivitis and meningitis either alone or as classical syndromes. The common mycoplasma includes Mycoplasma mycoides subspecies mycoides, M. mycoides subsp. capri, M. capricolum subsp. capripneumoniae, M. capricolum subsp. capricolum, M. agalactiae, M. bovis and $M$. conjunctivae etc. Most of the mycoplasmas produce a conglomerate of clinical signs hampering diagnosis. The other main challenge posed by mycoplasma is the difficulty in isolation due to lack of
\end{abstract}

* Corresponding author

E-mail: iqbalyatoo@gmail.com (Dr. Mohd. Iqbal Yatoo); rajneeshrana01@yahoo.com (Dr. Rajneesh Rana)

Peer review under responsibility of Journal of Experimental Biology and Agricultural Sciences.

Production and Hosting by Horizon Publisher India [HPI] (http://www.horizonpublisherindia.in/).

All rights reserved.
All the article published by Journal of Experimental Biology and Agricultural Sciences is licensed under a Creative Commons Attribution-NonCommercial 4.0 International License Based on a work at www.jebas.org.

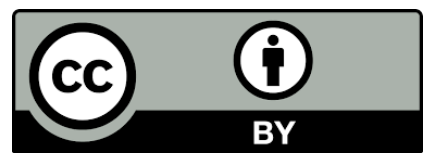




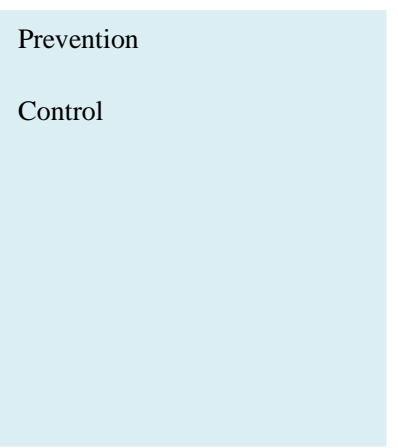

\section{Introduction}

Mycoplasmosis are the infectious diseases caused by smallest wall less prokaryotes known as mycoplasma (Nicholet, 1996; Kumar et al., 2011a). It is now an emerging threat and transboundary epidemiological disease posing a worldwide regulation on small ruminant productions and hence huge economic constraints for farmers and small ruminant rearing countries (Thiaucourt \& Bolske, 1996; Ruffin, 2001; Kumar et al., 2011a; Chakraborty et al., 2014; Prats-van der Ham et al., 2015). The pathogens of these diseases have autonomous replication and are extracellular parasites on mucous membranes in animals (Razin et al., 1998). They are mostly commensals but can cause heavy morbidity and mortality under favourable circumstances (Tigga et al., 2014). This mycoplasma class comprises of four orders having several families and more than 160 species affecting animals and humans (DaMassa, 1996; Nicholas, 2002; Kumar et al., 2014). The common mycoplasmal pathogens are $M$. mycoides subsp. mycoides (cattle), M. mycoides subsp. capri (goats), M. ovipneumoniae (sheep), M. putrefaciens (goats), Mycoplasma capricolum subsp. capripneumoniae or F38-like group of MacOwan (goats), M. conjunctivae (sheep), M. leachii (cattle), $M$. alvi (cattle), M. capricolum subsp. capricolum (goats), $M$. alkalescens (cattle), M. arginini (all ruminants), M. canadense (cattle), ovine/caprine group 5 of Al-Aubaidi, M. agalactiae (goats and sheep), M. bovigenitalium (cattle), M. bovis (cattle), M. californicum (cattle), M. verecundum (cattle), ovine/caprine groups 11 and 5 of Al-Aubaidi (Nicholas 2002; Kumar et al., 2011b; Kumar et al., 2014; Chakraborty et al., 2014).

Common mycoplasmal diseases include contagious caprine pleuropneumonia, contagious agalactia, pneumonias, besides arthritis, mastitis, seminal vesiculitis, ampullitis, epididymitis, orchitis, urethritis, conjunctivitis and meningitis either alone or as classical syndromes (Nayak \& Bhowmik, 1990b; DaMassa, 1996; Thiaucourt \& Bolske, 1996; Kumar et al., 2014). These diseases produce a conglomerate of clinical signs including respiratory signs, genito-urogenital signs, mastitis, arthritis, conjunctivitis and nervous signs thus making clinical diagnosis difficult (Priya et al.,
2008; Ravishankar et al., 2011; Awati \& Chavhan, 2013; Chakraborty et al., 2014). Some mycoplasmal infections though produce distinct signs but two or more organisms share the clinical outcome hindering further clinical diagnosis (Thiaucourt \& Bolske, 1996; DaMassa, 1996; Nicholas, 2002; Chakraborty et al., 2014). Postmortem lesions and pathological changes can provide a valuable diagnostic tool for which morbid material or tissue is prerequisite and the cumbersome process requires expert sampling, laboratory efficient processing and expert interpretation (DaMassa, 1996; Kusiluka et al., 2000; Nicholas, 2002; Chakraborty et al., 2014). Hence for better diagnosis, laboratory diagnosis is important of which isolation and identification is considered as gold standard method of diagnosis (Thiaucourt \& Bolske, 1996; DaMassa, 1996; Nicholas, 2002; Chakraborty et al., 2014). Laboratory diagnosis involves an efficient sampling protocol, expensive but highly specific cultural media and culturing techniques, isolation in a well-equipped and safe laboratory, identification and characterization by specific and sensitive methods involving colony characteristics, staining, morphology, biochemical testing, agglutination, complement fixation, enzyme-linked immunosorbent assay (ELISA), polymerase chain reaction (PCR), and genome sequencing (Manso-Silván et al., 2011; Chakraborty et al., 2014; TatayDualde et al., 2015; Tatay-Dualde et al., 2016). A combined group of tests can be applied together (multiplex PCR) (Manso-Silván et al., 2011; Chakraborty et al., 2014; Prats-van der Ham et al., 2015). Conventional laboratory tests are affordable but are hectic both due to mycoplasmal fastidious nature, slow growth and rapid loss, and specific growth requirements while as the modern tests are costly and not available in all countries (Thiaucourt et al., 1996; Thiaucourt \& Bolske, 1996; DaMassa, 1996; Nicholas, 2002; Chakraborty et al., 2014).

Prophylactic measures are prerequisite for prevention and control of mycoplasmosis keeping in view the frequent occurrence of outbreaks in small ruminants (Rurangirwa et al., 1987a; Thiaucourt et al., 1996; Kumar et al., 2009; Kumar et al., 2014). It will also minimize cost involvement for the treatment of affected animals. However vaccines are generally lacking in India and in 
most parts of the world. It needs to be developed from local isolates of mycoplasma. Novel vaccine development may be focused on recombinant vaccines, DNA vaccines, mycoplasma specific lipoprotein and polysaccharide utilization (Nicholas et al., 2009; Kumar et al., 2009; Kumar et al., 2014; Thankappan et al., 2017).

Till the vaccines are commercially available and affordable, the therapeutic efforts with commonly available antibiotics are going to be in use both in sporadic cases and outbreaks. However the usual practice is of using antibiotics for treating affected animals even before diagnosis. Oxyteracycline being the popular and the commonest antibiotic among herds men. Other commonly available and used antibiotics include enrofloxacin, streptomycin, gentamicin, whereas rarely available ones are tylosin, florfenicol, tiamulin and danofloxacin (Sarkar et al., 1992; Bergonier et al., 1997; Kumar et al., 2012; Abraham et al., 2015). Antibiotic resistance is already in rise against many antibiotics by different mycoplasma (Tatay-Dualde et al., 2017; Prats-van der Ham et al 2017). More therapeutic trials are required for evaluating better curative protocols so as to minimize the risk of antibiotic resistance.

Keeping in view all these lacunae and prospects for better combating the mycoplasmosis in small ruminants thrust should be given on novel and advanced methods of diagnosis with high specificity and sensitivity for confirmation followed by development of prophylactic measures using locally isolated mollicute strain along with highly efficacious, affordable and easily available therapeutics for curing the ailing animals.

\section{Etiologies}

A number of mycoplasma have been reported as cause of mycoplasmosis in sheep and goats in India causing various diseases (Thiaucourt \& Bolske, 1996; Kumar et al., 2013; Chakraborty et al., 2014; Jain et al., 2015). Mycoplasma mycoides cluster group have five species as important pathogens for small ruminants (Nicholas et al., 2009; Chakraborty et al., 2014). These members include $M$. mycoides subsp. mycoides, M. mycoides subsp. capri (Mmc), M. capricolum subsp. capricolum (Mcc), M. capricolum subsp. capripneumoniae (Mccp) and M. leachii and are closely interrelated both serologically and genetically (MansoSilván et al., 2009; Kumar et al., 2013; Chakraborty et al., 2014).

More than 160 species of mycoplasma are affecting animals and humans, the common mycoplasmal pathogens of sheep and goat are M. mycoides subsp. capri (goats), M. ovipneumoniae (sheep), M. putrefaciens (goats), M. capricolum subsp. capripneumonia or F38-like group of MacOwan (goats), M. conjunctivae (sheep), $M$. capricolum subsp. capricolum (goats), M. arginini (all ruminants), ovine/caprine group 5 of Al-Aubaidi, M. agalactiae (goats and sheep), ovine/caprine groups 11 and 5 of Al-Aubaidi (Leach, 1967; Al-Aubaidi, 1972; Cottew \& Yeats, 1978; Erno et al., 1983). Respiratory disease of high severity caused by $M$. capricolum subsp. capripneumoniae has been observed in goats and mainly predispose due to stressful conditions viz., transportation, overcrowding; sudden changes in environment etc (Gonçalves et al., 2010; Rifatbegović et al., 2011; Rahal et al., 2014).

A number of mycoplasma have been isolated or identified as etiological agents of mycoplasmosis in sheep and goat in India also. M. agalactiae has been reported in goats affected with granular vulvovaginitis (GW) (Singh et al., 1974). Kumar \& Chandiramani (1987) also isolated and characterized $M$. agalactiae from premature born kids. Kumar et al. (2011a) isolated, identified and molecularly characterized mycoplasma isolates from goats of Gujarat State in India and found $M$. mycoides subsp. capri, M. agalactiae, M. capricolum subsp. capricolum (Mcc), as the main isolates. Mccp has been isolated in India (Rurangirwa \& McGuire, 1996; Kumar \& Garg, 1991). $\mathrm{Mmm}$ was once believed to be a major cause of disease in goats in India (Rurangirwa \& McGuire, 1996). Mycoplasma bovis was isolated and characterized by Kumar et al. (2012) in sheep suffering from pneumonia whereas that of $M$. mycoides subsp capri from milk of natural goat mastitis cases by Kumar et al. (2013). M. capricolum subsp. capripneumoniae (Mccp) has been reported from different parts of the world in goats affected with contagious caprine pleuropneumonia (CCPP) (Walker, 1914; Suryawanshi et al., 2015; Sheikh et al., 2016; Yatoo \& Kanwar, 2016). Gupta et al. (1984) studied etiopathology of CCPP in goats. Mccp is grouped in M. mycoides cluster. M. mycoides subsp. capri affect small ruminants in similar way but may additionally cause extrapulmonary signs and lesions (Ravishankar et al., 2011).

Walker (1914) observed CCPP in goats in Kangra district of then Punjab. Kumar \& Garg (1991) isolated Mycoplasma F-38 from the milk of mastitic cows. Srivastava et al. (2000) isolated $M$. mycoides subsp. mycoides small colony type from contagious caprine pleuropneumonia affected animals in India. M. mycoides subsp. mycoides type LC was isolated by Singh et al. (2004) from caprine arthritis affected goats. M. agalactiae (Ma), M. mycoides subsp. capri (Mmc) and M. mycoides subsp. mycoides LC (Mmm) were identified by Mondal et al. (2004) from West Bengal, India. Roy et al. (2010) detected antibodies of Mycoplasma capri in goats of Gujarat state. When considering the published literature about clinical descriptions, the disease is posed to be endemic in different states of India (Walker, 1914; Rurangirwa \& McGuire, 1996; Thiaucourt \& Bolske, 1996; Srivastava et al., 2000). M. mycoides subsp. capri (Mmc) and M. mycoides subsp. mycoides LC (MmLC) have been erroneously referred as CCPP in India 
Table 1 Different species and subspecies of Mycoplasma along with the host and the disease it causes

\begin{tabular}{|c|c|c|c|}
\hline Mycoplasma & Hosts & Primary site of isolation (other) & Disease \\
\hline M. capricolum subsp. capripneumoniae & Goat (sheep) & Lungs & CCPP \\
\hline M. mycoides subsp. capri & Goat (sheep) & Respiratory tract (joints) & Plp, A, C \\
\hline M. capricolum subsp. capricolum & Goat, sheep & Joints/resp. tract (udder) & Plp, M, A \\
\hline M. ovipneumoniae & Sheep, goat & Respiratory tract & $\mathrm{P}$ \\
\hline M. conjunctivae & Sheep, goat & Eyes & $\mathrm{KC}$ \\
\hline M. agalactiae & Sheep, goat & Udder (joints, eyes) & M, A, Ke, P, S \\
\hline M. putrefaciens & Goat (sheep) & Udder (joints) & M, A \\
\hline M. arginini & Ubiquitous & Respiratory tract & None \\
\hline
\end{tabular}

(Nicholas et al., 2008) which is now believed to be endemic (Walker, 1914; Srivastava et al., 2000; Prats-van der Ham et al., 2015). Different species and subspecies of Mycoplasma along with the host, and the disease it causes have been given in Table 1 .

\section{Occurrence}

Occurrence of mycoplasmosis in India has been noted from time to time with the report of Walker (1914) being the earliest however some believe that in India outbreaks of CCPP occurred as early as 1889 from Bombay (Verma, 2000). Bawa (1944) reported occurrence of contagious agalactia for the first time in India. Since then a large number of outbreaks or isolated cases of mycoplasmosis have been reported from different parts of the country and continue to exist in many states of the country including Jammu and Kashmir, Himachal Pradesh, Punjab, Madhya Pradesh, Maharashtra, Chatisgarh, Ranchi, West Bengal, Gujarat, Tamil Nadu, Karnataka, Kerala (Kannur district), Uttar Pradesh and Tripura (Ingle et al. 2008; Priya et al., 2008; Ramdeva et al., 2008; Ravishankar et al., 2011; Awati \& Chavhan, 2013; Sheikh et al., 2008; Yatoo et al., 2014; Sheikh et al., 2016; Yatoo \& Kanwar, 2016).

Occurrence of CCPP in Ladakh (Jammu and Kashmir) can be inferred from the fact that the clinical cases of CCPP are routinely observed in the region which presents typical clinical signs and postmortem lesions of CCPP (Sheikh et al., 2008; Yatoo et al., 2014; Sheikh et al., 2016). Also occurrence of CCPP in surrounding states like Himachal Pradesh, Punjab (Walker, 1914; Srivastava et al., 2000) or neighboring countries like China (Chu et al., 2011), Pakistan (Awan et al., 2010; Samiullah, 2013), Afghanistan and Tajikistan (Peyraud et al., 2014) can influence occurrence in this region being in close proximity. Occurrence of
CCPP in surrounding wild animal species can also be a reason (Yu et al., 2013).

Among the mycoplasma infections, CCPP is of major pathogenic concern It has become the main challenge and emerging threat to goat population in the country including pashmina goats in Changthang, Ladakh (Sheikh et al., 2008; Yatoo et al., 2014; Sheikh et al., 2016; Yatoo \& Kanwar, 2016). CCPP has been noted in Maharashtra by Suryawanshi et al. (2015) and Ingle et al. (2008), in Jabalpur by Gupta et al. (2016), in Kerala by Abraham et al. (2015); Ravishankar et al. (2011) and Priya et al. (2008), in Tripura by Ghosh et al. (1989), in West Bengal by Guha et al. (1985) and Ravishankar et al. (2011) in Kanur Kerala, and Priya et al. (2008) in Wayanad district of Kerala. The clinical cases of CCPP in pashmina goats of Changthang, Ladakh and in Bakarwal goats of Kashmir valley were also observed with no isolation report of the organism.

Mycoplasmosis can occur in any age group however young and immunocompromised animals are mainly susceptible especially under harsh environmental conditions. Seasonal events can also affect occurrence e.g. outbreaks after heavy rains or after cold spells. Man-made stressful events like transportation over long distances can also affect occurrence. Stress can suppress immunity thus aggravating infection in carrier animals allowing shedding of pathogens (OIE, 2009).

CCPP though frequently affects goat but occasional harbouring in sheep has also been noted (Sadique et al., 2012). In some cases high rates of morbidity, such as in recent outbreaks in Turkey, India or Iran or high sero-prevalences has been recorded. Further studies are required to know the real epidemiology of the disease, although some authors do assume its participation in the maintenance and dissemination of CCPP (Yu et al., 2013). Others 
believe that it does not affect sheep or cattle and does not produce local oedematous reactions when injected subcutaneously (MacOwan \& Minette, 1976; Rurangirwa \& McGuire, 1996). Dinesh et al. (2013) noted involvement of genetic and non-genetic factors on sero-prevalance of Mycoplasma mycoides subsp. capri in goat.

\section{Epidemiology}

\subsection{Prevalence, Morbidity, Mortality}

The prevalence of mycoplasmosis in different states of India is variable. Though more studies are to be undertaken in most of the states but in some states a few studies on different species and subspecies of mycoplasma have been reported. This might be due to lack of facilities to diagnose the disease, cost involvement in media and culturing and lack of technical expertise. The fastidious nature, slow growth and special requirements of mycoplasma also hamper studies. Still attempts have been made through diverse methods based on serology like agglutination tests and amplification of genome by polymerase chain reaction, to overcome difficulties in diagnosis and reporting of disease. However cross reactions, less accuracy in procedures, and low specificity and sensitivity have led to misinterpretation of disease prevalence (Nicholas et al., 2008) also. Application of novel tests like RFLP, cELISA, and real time PCR which have been utilized in many studies (Woubit et al., 2004; Awan et al., 2010; Peyraud et al., 2014) can also be used in most of the affected parts in India. With whatsoever available tests, the complete flocks screening is required. This may be further helpful to know the actual prevalence in India.

Ghosh et al. (1989) has reported 9.09 to $63.64 \%$ prevalence of CCPP in goats of Tripura state. Pradhan (1997) has reported $27.00 \%$ and Shaheen et al. (2001) reported $31.37 \%$ prevalence. Mondal et al. (2004) found that out of 4500 suspected mycoplasma infected swabs samples, 102 were positive for Mycoplasma agalactiae (Ma), 124 for Mycoplasma mycoides subsp. capri (Mmc) and 84 for M. mycoides subsp. mycoides LC (Mmm). Barbuddhe et al. (2005) reported 26.43\% prevalence of CCPP in goats. Ramdeva et al. (2008) reported sero-prevalence of $5.02 \%$ of CCPP in goats and $4.44 \%$ in sheep in Himachal Pradesh. Ingle et al. (2008) have reported $33.67 \%$ prevalence of CCPP in goats of Nagpur district of Vidarbha region of Maharashtra. Kumar et al. (2011b) studied mycoplasmosis in Gujarat and 8.35 $\%$ of samples (30 out of 358) were of Mycoplasma species, the isolates were further characterized biochemically and identified as M. mycoides subsp. capri and M. capricolum subsp. capricolum by PCR and PCR-RFLP. Awati \& Chavhan (2013) have reported a sero-prevalence of $35 \%$ in small ruminants in North Karnataka. Jain et al. (2015) studied mycoplasmosis in Barbari goats, 838 samples of Barbari goats from different districts of Uttar Pradesh were tested for the presence of Mycoplasmas. Of these, 68 (8.11\%) yielded Mycoplasmas. The prevalence was highest in adult goats. Geographical variation was not noted when the prevalence was higher in winter thus indicating that the Mycoplasmas are prevalent in goats of this region. It is estimated that pneumonia alone causes at least $10 \%$ mortality in sheep population in India of which Mycoplasma is an important cause (Maru et al., 1990; Jana et al., 2005). Gupta et al. (2015) also studied the identification of Mycoplasma species in ruminants with ocular infections. They used species-specific PCR tests for chlamydiae and mycoplasmas followed by nucleotide sequence analysis and observed 41.93, 14.29 and $37.5 \%$ prevalence of mycoplasma infection in ovine, caprine and bovines, respectively. Recently M. arginini was also observed as one of the important Mycoplasma which is found to be frequently associated with caprine pneumonia (Rekha et al., 2017)

A greater incidence of respiratory infections (especially pneumonia) has been reported in goats from India by Udit \& Chand (2008) who have detected Mycoplasma in several samples. Reporting of the presence of $M$. capricolum subsp. capripneumoniae in nasal swabs collected from goats has also been done from neighboring Pakistan by Awan et al. (2009). Tiwari et al. (2015) has studied sero-prevalence of contagious agalactia in goats by slide agglutination test. The overall seroprevalence of contagious agalactia was $9.50 \%$. Organized goat farms showed higher prevalence $(19.65 \%)$ than in unorganised sector of goatry (4.62\%). Barbari breed showed 34.69\% prevalence followed by $21.43 \%$ in Black Bengal breed, $17.48 \%$ in Sirohi breed, $9.09 \%$ in Jamunapari breed and the lowest prevalence of $2.77 \%$ was noted in non-descript breed of goats. Gupta et al. (2016) noted that overall sero-prevalence of CCPP in goats was $10.65 \%$. Sero-prevalence of CCPP in organised goatry was higher (i.e. $13.54 \%$ ) than the unorganised sector of goatry (i.e. $9.01 \%$ ). Sex wise sero-prevalence was marginally higher in female $(10.67 \%)$ than the male $(10.61 \%)$.

This indicates occurrence of mycoplasmosis in different states of country. However confirmatory diagnosis of disease is utmost essential for its successful prediction and eradication. In India, till date, no commercial diagnostic antigen or kit is available for diagnosis of mycoplasmal diseases in goats. Hence seroprevalence of the disease is not well known in different states of the country. Almost $7-11 \%$ of disease outbreaks are having clinical resemblance to CCPP (commonly known as Caprine Pleuropneumonia) in pashmina goats (Yatoo \& Kanwar, 2016; Sheikh et al., 2016). It causes huge morbidity (90-100\%) and mortality (70-90\%) in pashmina goats. Clinical outbreaks of CCPP in a flock often show $100 \%$ morbidity and mortality rate of 60 to $70 \%$ in untreated cases. A morbidity of $80 \%$ and mortality of $62 \%$ were recorded in CCPP by Abraham et al. (2015). Sheikh 
et al. (2016) has also quoted a sero-prevalnce of $36.5 \%$ (69 out of 200 cases) of CCPP in pashmina goats. Treatment has reduced morbidity and mortality to $16.66 \%$ and $9.16 \%$ against $100 \%$ and $66.66 \%$ respectively. Hussain et al. (2012) reported a mortality of 9.17\% due to CCPP. Ravishankar et al. (2011) showed $62.5 \%$ antimycoplasma antibodies on rapid plate agglutination test in goats. Abraham et al. (2015) noted higher morbidity (80\%) and mortality (62\%) in CCPP outbreak.

It is very crucial to note that the evolution as well as dynamics of various strains of $M$. capricolum subsp. capripneumoniae (Mccp) must be studied comprehensively for understanding the CCPP epidemiology. Robust genotyping tools along with molecular advances are required for conducting investigations in relation to molecular epidemiology. The 16S rRNA gene formed the initial basis of molecular epidemiological studies viz., phylogenetic analyses of different strains of Mccp. It is hypothetical to know the polymorphism, if exist to certain extent between two gene copies (16S rRNA) of the strains of Mccp. This has ultimately allowed the use of this very particular housekeeping gene for combining analyses for both evolutionary as well as epidemiological investigations (Pettersson et al., 1998; Dupuy et al., 2015).

\section{Economic impacts}

Mycoplasma cause severe and contagious diseases in small ruminants, with significant economic impact (OIE 2017a). Economic losses due to mycoplasmosis are both by morbidity, mortality and decline or loss of production performance. Mycoplasmosis in small ruminants has greater impact as usually it is a rapidly spreading epidemic involving large population thus affecting in outbreak forms mostly. Morbidity causes constraints in livestock management, overburdens with costs of treatment, and imposes restriction on trade or transport. Mortality causes direct loss by death of the valuable animals. Diseased animals are usually culled in developed countries, which is not possible in India and have low production and quality of products is poor. Loss on production performance is severe. CCPP causes huge economic losses to Changpas, who are directly dependent (90$100 \%)$ on traditional and nationally important venture-pashmina farming (Yatoo et al., 2014) and contribute $80 \%$ (45-50 tons) to national output (60 tons) of pashmina. Losses are both due to morbidity and mortality leading to production loss in affected animals, costs for diagnosis and treatment. In present study we noted a loss of around $28.48 \%$ in pashmina yield in CCPP affected goats and a benefit cost ratio of 2.79 in untreated animals against 8.76 in treated animals. Hence CCPP causes economic loss to pashmina farmers. Besides insecurity of spread of disease in other disease free areas is the cause of concern. The restriction in suspected / affected animal mobility is essentially required.

\section{Clinical signs of mycoplasmosis}

Clinical signs of mycoplasmosis are highly variable and usually not specific hence confusing. They range from respiratory, genitoreproductive, mastitis, arthritis, conjunctivitis, skeletal, and nervous signs due to involvement of various systems (Lambert, 1987; DaMassa et al., 1992; Thiaucourt \& Bolske, 1996; Kumar et al., 2014). Different mycoplasma species also produce clinical signs similar to other members making clinical diagnosis further complicated. Some species are peculiar for certain clinical signs but cannot be considered confirmatory (Lambert, 1987; DaMassa et al., 1992; Thiaucourt \& Bolske, 1996; Kumar et al., 2014). Clinical signs can be variable as per subspecies also as contagious caprine pleuropneumonia (CCPP) is caused by M. capricolum subspecies capripneumoniae (Mccp), atypical pneumonia by $M$. ovipneumoniae, and infectious keratoconjunctivitis by $M$. conjunctivae.

Clinically, mycoplasma infections are usually difficult to ascertain as clinical signs resemble other infections. They often lack pathognomonic characteristics, and symptoms can be shared or mimic other infections (Kumar et al., 2013; Kumar et al., 2014; Chakraborty et al., 2014; Jain et al., 2015). Hence diagnosis is usually misinterpreted (DaMassa et al., 1992; Thiaucourt \& Bolske, 1996; Nicholas et al., 2008; Chakraborty et al., 2014, Tiwari et al., 2015). In acute or peracute infections animal dies without premonitory signs (DaMassa et al., 1992; Thiaucourt \& Bolske, 1996,). They show no or slight histologic changes. Some cases can also be undetermined if of diagnostic significance (DaMassa et al., 1992; Thiaucourt \& Bolske, 1996). However some mycoplasma are peculiar in their signs like pleuropneumonia in CCPP by Mccp, bovine arthritis and mastitis by $M$. leachii, when the other members cause MAKePS syndrome (Mastitis, Arthritis, Keratoconjunctivitis, Pneumonia, Septicaemia) which is shared by $M$. agalactiae and $M$. putrifaciens in goats (Thiaucourt \& Bolske, 1996). However even in these diseases some have reported unusual signs e.g. inflammation of joints in CCPP (Mondal et al., 2004) which is unlikely but can be MmLC infection which causes arthritis and mastitis in goats (DaMassa et al., 1992; Sadique et al., 2012).

The systemic involvement of different organs accompanied by high fever suggested the septicemic nature of disease. Singh et al. (1974) found that granular vulvovaginitis (GW) in goats associated with Mycoplasma agalactiae. Fever, anorexia, depression, coughing, nasal discharge, lagging, lying down, pleurodynae (thorax pain), arthritis, mastitis, keratoconjuctivits, nervousness and loss of body weight are the constellation of signs usually exhibited in mycoplasma infections and noted in different diseases in sheep and goat (Srivastava \& Singh, 2000; Priya et al., 2008; Ingle et al., 2008; Awati \& Chavhan 2013; Abraham et al., 
2015; Sheikh et al., 2016; Yatoo \& Kanwar, 2016). The most consistent clinical findings of mycoplasmosis are mild to severe cough, purulent nasal discharge, emaciation, dyspnea, increased respiration rate, and pyrexia (Hussain et al., 2012). Mycoplasma pneumonia in goats were characterized by rise of temperature $\left(40-43^{\circ} \mathrm{C}\right)$, marked depression, tremor, reluctance to move, painful accelerated respiration, cough, partial to complete closure of nostril, nasal discharge, anorexia, low tone bleating, recumbency and few cases of arthritis and corneal opacity. Haematologically, anaemia with leutocytosis followed by leucoponia is noted (Mondal et al., 2004). In CCPP fever, nasal discharge, cough, respiratory distress and grunting has been noted in goats (Ravishankar et al., 2011). Similarly Abraham et al. (2015) also noted fever, coughing, dyspnea and frothy nasal discharge presented before before death in CCPP affected goats.

In Mycoplasma agalactiae infection, the inflammation of mammary gland is initially caused due to connective tissue involvement in the udder. Ultimately there is development of mastitis (catarrhal/ parencymatous) that subsequently leads to atrophy and then agalactia. Colostrum of affected animals is a source of infection to kids. Pleurisy; joint pains (along with synovial fluid accumulation); arthritis (involving carpal as well as tarsal joints) in goats are common. There may be development of ankylosis if animals suffer from chronic infection. The cornea may get affected leading to keratoconjunctivitis ultimately resulting in blindness. There may be vulvovaginitis (granular) in goats (Real et al., 1994; Madanat et al., 2001; Kumar et al., 2014).

\section{Pathogenesis of mycoplasmosis}

Pathogenesis of mycoplasmosis is correlated to severity of pathogen and acuteness of disease. Some mycoplasma are less pathogenic (M. ovipneumoniae) whereas others highly pathogenic (M. capricolum subspecies capripneumoniae). Few mycoplasma results in mild disease (M. ovipneumoniae) while others in very severe and usually fatal disease (M. capricolum subspecies capripneumoniae). Pathogenesis involves gross and histopathological lesions due to inflammatory reactions in various tissues of different organs like lungs (pneumonia), joints (arthritis), udder (mastitis), and conjunctiva (conjuctivitis). Pathological lesions have been enumerated in diverse cases and outbreaks of mycoplasmosis (Gupta et al., 1984; Mohan \& Obwolo, 1990; Sheikh et al., 2016). Macroscopic changes include pleural exudation, thickening of septa, congestion and necrosis of lungs, marbled appearance, hepatisation, cellulitis, inflamed mucous membranes, serosa, fluid exudation in joints, swelling, inflamed udder, hardening, conjunctivitis, lacrymation, laceration, vulvovaginitis, and discharges (Darzi et al., 1998; Chakraborty et al., 2014; Sheikh et al., 2016). The ophthalmic affections grossly show increased lacrimation, lymph follicles of the third eyelid are increased, conjunctiva show hyperemia, and corneal opacity occurs. Sometimes a rim of vessels extending from the limbus into the cornea occurs.

The host as well as tissue specificity of the etiological agent is a characteristic feature of the disease CCPP due to the appearance of lesions solely in the lungs of goats. It has been found that certain Mycoplasmas possess adhesions but such component is yet to be recorded for $M$. capricolum subsp. capripneumoniae (Mccp). The affected goat lungs however contain the organism in greater concentration but the organisms are not disseminated to other organs. This is actually the result of specific reaction of the tissue of lungs to components of the organism ultimately leading to an aggravated inflammatory reaction (Thiaucourt \& Bölske, 1996). Pneumonic cases showed consolidation of lungs; alveolar exudation and pleural adhesion in CCPP affected Beetal goats (Hussain et al., 2012) while as patho-morphological findings revealed congested trachea, frothy exudates, chronic tracheitis, enlarged and swollen lymph nodes, unilateral or bilateral pneumonia, serosanguineous strands in pericardium and peritoneum, enlarged liver and kidney with few necrotic foci in mycoplasma affected goats (Mondal et al., 2004). Abraham et al. (2015) observed classical lesions of CCPP in an outbreak which were confined to thoracic cavity with extensive pleuritis, accumulation of clear straw coloured fluid and fibrin flocculations in the thoracic cavity. Lungs were adhered with large fibrin clots and were severely consolidated. Massive hepatisation was seen along with granulation in sections and thickening of pleura. Lesions were unilateral in most of the cases. Lesions were organized (Abraham et al., 2015). For Mycoplasma agalactiae, the predilection site (primary) is the respiratory tract mucosa along with mammary gland alveoli; and small intestine. Once infected the affected animals show signs of fever because of bacteremia. Subsequently there is dissemination of the organisms via circulation to various vital organs. It is important to note in this regard that disease condition involving small intestine has not been reported (Bergonier et al., 1997; Kizil \& Ozdemir, 2006; Kumar et al., 2014).

Microscopic lesions in mycoplasmosis include fibrinous infiltration in alveolar tissue (fibrinous pleuropneumonia), pericardium, neutrophilic infiltration in pulmonary tissue, sequestrum formation in lungs, thickening of septa between alveoli and lobules, pulmonary emphysema, atelectasis, thickening of interlobular septa, rarely abscess formation in lungs, heart, liver and kidney. Cellulitis is common at the site of infection. Arthritis in mycoplasma infection may be of severe fibrinopurulent type affecting nearly all joints, surrounded by congestion and edema. Fibrin deposition in joint and hemorrhagic erosions of the articular cartilages is noted (DaMassa et al. 1992). Microscopically lesions included conjunctivitis of eyelids, 
extensive subepithelial infiltration of mononuclear cells, hyperemia, endothelial swelling, and increase in number and size of lymph follicles (DaMassa et al., 1992). Denudation of layers in conjunctiva, vulvo-vagina, diarthroidal joints is also noted (DaMassa et al., 1992)

Mycoplasmosis involves fluid leakage from the vasculature as primary histologic change, with moderate to marked leukocyte exudation. Diffuse interstitial pneumonia, exudate in the alveoli and alveolar walls and alveoli having diffuse monocytemacrophage accumulation. Histiocytic meningitis, acute vessel wall necrosis and moderate necrosis of sinusoidal cells in spleen, diffuse neutrophilic infiltration in the hepatic sinusoids and glomeruli is noted in few cases. Joint cavity filled with fibrin, neutrophil exudation, necrosis of the synovial lining and collagenous stroma surrounding the joints laden with foci of coagulative necrosis. Fibrinous, leukocytic thrombi in the lungs, liver, and meningeal vessels may also be seen (DaMassa et al., 1992).

Sheikh et al. (2016) and Yatoo \& Kanwar (2016) quoted similar findings of histopathological changes in pashmina goats affected with CCPP. Grossly there was large quantity of serofibrinous fluid, heavy fibrin deposition, and severe congestion of lungs, marbled appearance, necrosis and liver like consistency. Microscopically fibrinous infiltration, neutrophilic infiltration, septa was not thickened except in few; similar was case with pulmonary emphysema and atelectasis. Gupta et al. (1984), Mohan \& Obwolo (1990), Darzi et al. (1998), Kumar et al. (2010) and Sadique et al. (2012) have also noted similar pathological changes in CCPP affected goats and experimental animals. Histopathologically, septal peribronchiolar fibrosis was the main lesions followed by fibrinous pleuritis and peribronchiolar cuffing of mononuclear cells in lungs of CCPP affected Beetal goats (Hussain et al., 2012). Trachea was erosive, edematous and haemorrhagic (Mondal et al., 2004). Blood vessels were haemorrhagic in lungs, necrosis of lining cells, infiltration with neutrophils, lymphocytes and macrophages along with thrombosis and emphysema. Congestion with involvement of central vein area in liver and glomerulonephritis and cellular infiltration in kidney were found.

Microscopically, acute fibrino necrotic pleuropneumonia has been noted in lung tissue section of CCPP affected goats, with extensive vascular congestion, hemorrhage, perivascular infiltration and mononuclear infiltration in parenchyma (Abraham et al., 2015). Loss of architecture of lung parenchyma, necrotic cellular exudates in alveolar lumen, intra lobular oedema was prominent (Abraham et al., 2015). Interstitial, intralobular oedema of the lung is main feature of Mccp infection compared with the thickening of the interlobular septa with $\mathrm{Mmc}$ and $\mathrm{Mmm}$ (MacOwan \& Minette, 1976; Rurangirwa \& McGuire, 1996).
In accordance with their potential pathogenicity and their localization, mollicutes are usually involved in respiratory diseases, skeletal diseases, udder affections, ophthalmic infections and diseases of the urogenital tract. As with all other infectious agents, the outcome of the host/agent interaction depends on the resistance of the host, the number and virulence of the mycoplasmas as well as the external environment, which here includes the overall pressure of infection. It is therefore not surprising that when the resistance, either of a single animal or a group of animals, is lowered, mycoplasmaemia may develop, leading to clinical manifestations in a number of anatomical sites, either at sites of low resistance or under normal anatomical and physiological conditions. Mycoplasmas may therefore be involved in pneumonia, mastitis, arthritis, seminal vesiculitis, ampullitis, epididymitis, orchitis, urethritis, conjunctivitis and meningitis in addition to those classical syndromes already mentioned. Spontaneous cases may arise in single animals or in groups of animals.

Mycoplasma being extracellular parasites of mucous membranes may adhere firmly to epithelial cells. However the molecular biology of this adherence is yet to be proven for Mccp. Adhesion favors colonization for setting up infection. Metabolic activity of mycoplasma release free radicals like hydrogen superoxide and super oxide radicals which can damage cilia or membranes of cells. Release of extracellular enzymes or toxins by mccp have not been investigated. The role of the capsules seen in some mycoplasmas, particularly the galactan of M. mycoides subsp. mycoides, is not clear either (Nicholet, 1996). Activation of host immune system by mccp though yet to be elucidated but has strong support of having major role in the pathogenesis of mycoplasmosis. Immune cell stimulation by antigens of mccp can aggravate or suppress immunity. The mitogenic stimulation of lymphocytes, antiphagocytic activity, immunosuppressive effects and auto-immune phenomena have been observed for many years in a variety of animals. Interaction of mycoplasmas with macrophages and monocytes induces the production of proinflammatory cytokines, such as the tumour necrosis factor $\alpha$, interleukins and interferon $\gamma$. Of importance are mycoplasma membrane lipoproteins and certain lipids, which induce cytokine secretion by a mechanism distinct from that of bacterial lipopolysaccharides (Razin \& Tully, 1995; Tully \& Razin, 1996; Nicholet, 1996). Superantigens can also stimulate autoimmune response in mycoplasmosis (Nicholet, 1996). Surface antigens including very immunogenic lipoproteins show antigenic variation hence escape immune system of host. Despite pathogenic mechanisms being variable mccp usually causes acute diseases in young and immunocompromised animals only especially under harsh climate and chronic disease in healthy resistant animals. Apparently healthy carriers play a dominant role in the epidemiology of mycoplasmosis. 


\section{Diagnosis}

The diagnosis of mycoplasmosis under routine Indian conditions involves history, clinical signs, physical examination followed by postmortem examination and histopathology. Rarely agglutination tests are done, if available. Sampling requires expertise and culture, isolation and identification requires specialized laboratory and infrastructure and costly media, hence is rarely practiced and not affordable in all states when most of the sheep and goat rearing states are facing problems of mycoplasmosis. The diagnostic methods like complement fixation test (CFT), enzymelinked immunosorbent assay (ELISA), polymerase chain reaction (PCR), sodium dodecyl sulfate polyacrylamide gel electrophoresis (SDS-PAGE), Restriction Fragment Length Polymorphism (RFLP) and DNA sequencing should be recommended to explore the disease situation in most states.

For diagnosis of mycoplasmosis the conventional methods include isolation in specific media, followed by biochemical characterization and staining (Chakraborty et al., 2014). Specific media recommended are modified Hank's Balanced Salt Solution Liquid Media (MBHS-L) for ovine and caprine mycoplasma (Nicholas, 2002; Kumar et al., 2012; Kumar et al., 2014), MacOwan and Minette's media to culture Mccp organisms (MacOwan \& Minette, 1976), termed as viande foie goat (VFG), and includes goat-meat liver broth and goat serum. Other media are WJ (Jones \& Wood, 1988), modified Hayflick's, and modified Newing's tryptose broth (Kibor \& Waiyaki, 1986). Mohan et al. (1990) and Thiaucourt et al. (1992) noted that media enriched with $0.2 \%$ (or up to $0.8 \%$ ) sodium pyruvate are better for primary isolation and antigen production of Mccp. In India usually culture is done in pleuropneumonia like organism (PPLO) broth constituting PPLO broth base $2.184 \mathrm{~g}, 8 \mathrm{ml}$ of $25 \%$ yeast extract, $16 \mathrm{ml}$ of inactivated horse serum, $0.8 \mathrm{ml}$ of $10 \%$ thallium acetate, $2 \mathrm{ml}$ of $25 \%$ sodium pyruvate, $1 \mathrm{ml}$ of $50 \%$ glucose and 40,000 IU of benzyl penicillin in $104 \mathrm{ml}$ water (Srivastava et al., 2000; Mondal et al., 2004; Kumar et al., 2011a; Kumar et al., 2013; Abraham et al., 2015; Jain et al., 2015). Staining is done by Gram stain, Giemsa stain, Diene's stain, acridine orange $\mathrm{R}$ stain (Mondal et al., 2004; Ravishankar et al., 2011; Abraham et al., 2015; Jain et al., 2015). DNA staining can be employed on cell culture (Young et al., 2010). Biochemical testing is usually done by digitonin sensitivity, glucose fermentation, sorbitol digestion, arginine decarboxylation, casein and serum digestion for identification of Mycoplasma species (Srivastava et al., 2000; Jain et al., 2015).

Growth inhibition, agar gel immunodiffusion, counter current immunoelectrophoresis, complement fixation, and PAGE were the usual serological tests used initially (Srivastava et al., 2000; Chakraborty et al., 2014; Jain et al., 2015; Saminathan et al., 2016). Cross-reactions with other mollicutes were main limitation of these tests hampering diagnosis (Thiaucourt \& Bolske, 1996, Chakraborty et al., 2014). Immunobinding assay with polyclonal sera was able to differentiate closely related species. This was followed by using specific and purified antigens by PAGE and SDS-PAGE for specific diagnostic purpose (Srivastava et al., 2000; Chakraborty et al., 2014; Kumar et al., 2014). Identification of novel antigens or proteins with SDS-PAGE and immunoblotting paves way for future diagnostics. They are the basis for sensitive and specific tests (Srivastava et al., 2000; Chakraborty et al., 2014; Kumar et al., 2014). Development of monoclonal antibodies may provide an improved diagnostic capability. Sensitive and specific ELISAs based on monoclonal antibodies from purified and specific immunogenic proteins led to better diagnosis (Peyraud et al., 2014; Chakraborty et al., 2014; Kumar et al., 2014; OIE, 2017b). Molecular evaluation of Mycoplasma species based on different set of primers to identify different species further aided in diagnosis process. For highly specific diagnostic test especially based on monoclonal antibody highly specific and potent antigenic protein is isolated in SDS-PAGE followed by western blotting using homo- and heterologous sera against different Mycoplasma species and subspecies (Srivastava et al., 2000; Chakraborty et al., 2014; Kumar et al., 2014; OIE, 2017a). Species and subspecies specific diagnostic proteins have become basis for development of many advanced tests for the detection of mycoplasma (Chakraborty et al., 2014; Kumar et al., 2014; OIE, 2017b).

PCR as well as PCR-RFLP are being used for molecular diagnosis of several clusters as well as groups using species specific primers (Chakraborty et al., 2014). Different techniques like Restriction Fragment Length Polymerase (RFLP) assay (Kumar et al., 2011b), Lateral Flow assay (Arun et al., 2014), Loop mediated Isothermal Amplification (LAMP) test (Rekha et al., 2014; Rekha et al., 2015) have been tried. Combination of conventional and advanced molecular tests is preferred for confirmation of field outbreaks. Growth inhibition test has been employed for identification of the Mccp agent followed by PCR. These tests help in differentiating $M$. capricolum and $M$. putrefaciens (Chakraborty et al., 2014). Recently multiplex PCRs are being used for diagnosis of mycoplasma infections (Chakraborty et al., 2014; Settypalli et al., 2016). This also helps in ruling out other infections (Chakraborty et al., 2014; Settypalli et al., 2016). Specific genes like arcD, polC and fusA are being explored for diagnostic purpose (Woubit et al., 2004; Chakraborty et al., 2014; Ambroset et al., 2017). Kashoo et al. (2013) conducted a study for amplification as well as cloning of the M. agalactiae p80 gene for which PCR assays (specific for $M$. agalactiae) have been employed. Self designing of the primers (gene specific) is a special feature of the study. This particular study is indicative of the fact that as far as investigation of contagious agalactia is concerned the use of $\mathrm{p} 80$ protein (conserved) aids to the 
specificity of diagnosis. It is important to note that some assays require further assessment of clinical specimens while others are very promising for large scale diagnosis and have field applicability (Chakraborty et al., 2014; Liljander et al. 2015). Mycoplasma mycoides subsp. capri (Mmc) has been detected from milk (bulk samples) of goats suffering from mastitis in an area affected with contagious agalactia by applying PCR. Experimental study has also indicated the usefulness of PCR to detect Mmc (Misri et al., 1988; Amores et al., 2012). The 16S amplified rDNA restriction analysis (16S ARDRA) has been employed for studying strain variation (intra species). Such study helped in recovering 3.5 per cent isolates of Mmc. 16S ARDRA has revealed multiple variants (intra species) among the isolates recovered. This study has lead to the conclusion that mycoplasmal mastitis may be caused by Mmc in goats in India (Kumar et al., 2013).

In accordance with Rurangirwa \& McGuire (1996), the general diagnosis of members of Mollicutes is based primarily on the following criteria: absence of a cell wall, typical "fried egg" appearance of the minute colonies, filtrability through a membrane filter of $450 \mathrm{~nm}$ pore diameter, and absence of reversion of fresh isolates to bacteria of divisions I, II or IV under appropriate conditions.

Since mollicutes do not have a cell wall, the micro-organisms of this group appear purplish-pink while staining with Giemsa stain. Identification procedures include biochemical and serological methods, and their interpretation depends on the combined results of a series of tests. Prior to any detailed examination, the culture must be pure. Once this result has been obtained (e.g. by a colony cloning procedure), the following steps, which are all described in great detail elsewhere (Rurangirwa \& McGuire, 1996; OIE, 2017a), are performed: a. Sensitivity to digitonin: Mycoplasmas and ureaplasmas are sensitive, while acholeplasmas are resistant. At this point the latter are subjected to serological examinations. b. Test for urease activity. The ureaplasmas are urease positive, while mycoplasmas are negative. At this point ureaplasmas are subjected to serological tests. c. Strains of genus Mycoplasma are examined using six biochemical tests: catabolism of glucose and arginine, phosphatase activity, digestion of coagulated horse serum, and reduction of tetrazolium chloride under aerobic and anaerobic conditions. Antisera for subsequent serological tests are selected according to the results of the first two tests, which reliably subdivide mycoplasmas into four biochemically defined groups. A further subdivision of these four groups may be attempted on the basis of phosphatase activity, but this property is subject to intra-species variability and even strain instability. Strains which digest serum are probably confined to the following species or groups: M. mycoides subsp. mycoides, and subsp. capri, M. capricolum, group 7 of Leach and the F38-like group of
MacOwan. d. Serological tests: A number of sera, selected according to the results of the above tests, is examined with the indirect immunofluorescence (IMF) test, using unfixed agar colonies. The IMF test depends primarily on surface antigens, is usually species-specific, and is easy to interpret. As a second step in serological examination, all sera reacting positively to IMF are subjected to the growth inhibition (GI) test, which also reveals surface antigens. As a final step, the growth precipitation test is recommended.

Keeping in view these points the specific and sensitive diagnosis of mycoplasmosis is utmost important for proper management of these diseases in India. Of the most significant importance are CCPP and contagious agalactia. Despite several diagnostic procedures confirmatory diagnosis is still not satisfactorily available probably due to multiple / mixed mollicutes etiology. Though in India the usual test used in most of the studies on mycoplasmosis is rapid plate agglutination test also called as slide agglutination test (Ravishankar et al. 2011; Awati \& Chavhan, 2013; Gupta et al., 2016) but has been misinterpreted for diagnostic test of CCPP in most of these studies and is not confirmatory for CCPP. Sometimes diagnosis based on one criterion has not followed other criteria e.g. CCPP diagnosed goats on PCR have not shown any pathogenic bacteria on impression smears of lungs and other visceral organs. Also cultural examination of heart blood and lungs were not conclusive (Abraham et al., 2015). Microbial culture, isolation and identification along with Giemsa staining and biochemical tests such as digitonin sensitivity, glucose fermentation, arginine decarboxylation, casein digestion for identification of Mycoplasma species were used by Jain et al. (2015). PCR, PAGE, immune binding assay were evaluated for the diagnosis of different mycoplasma by Kumar et al. (2001; 2002; 2010). PCR was used for confirmation of CCPP in goats in Kerala (Abraham et al., 2015). A genome fragment of Mycoplasma conjunctivae, causative agent of pink eye in sheep as well as goat, which is 750 base pairs in length has been amplified by PCR by using organism specific primers (Kumar et al., 2011a; Kumar et al., 2011b; Shahzadet al., 2013). A suitable LAMP test was developed for the diagnosis of Mycoplasma agalactiae the causative agent of contagious agalactia in goats with the detection level of $20 \mathrm{fg}$ DNA. The test could be performed with $70 \mathrm{~min}$. at $58^{\circ} \mathrm{C}$ constant temperature (Rekha et al., 2015). LAMP (Loop-Mediated Isothermal Amplification) were developed. This test provides a rapid and sensitive diagnosis in a rural environment, where no laboratory equipment was available. LAMP can be performed where thermocyclers cannot be easily maintained/ procured (Rekha et al., 2014). The advantage of these tests is no need of agarose gel electrophoresis. An attempt was also made for the development of Lateral flow test for the rapid detection of contagious agalactia in goats (Arun et al., 2014). 
From time to time the standardization of ELISA and PCR for the diagnosis of Mycoides clusters of Mycoplasma viz., Mycoplasma mycoides subsp. mycoides, Mycoplasma mycoides subsp. capri, M. capricolum subsp. capricolumn, M. capricolum, subsp. capripneumoniae and Mycoplasma leachii ( bovine group 7) are also observed (IVRI, 2016).

Rarely blood biochemistry is practiced and is usually of little diagnostic significance. Biochemical parameters like total protein, albumin were found lower in mycoplasma affected goats in comparison to control ones however SGOT, SGPT, serum calcium, blood sugar and globulin were increased (Mondal et al., 2004). Histopathological examination of gross and microscopic lesions is also being used for diagnosis (Mondal et al., 2004). Such approaches should be further explored for the holistic diagnosis. Hence species and subspecies specific diagnostic tests are needed for accurate and timely diagnosis of mycoplasmal diseases.

\section{Prevention and control}

Vaccines are of prime importance for the prevention and control of mycoplasmosis by using either locally or widely prevalent strains of the mollicute. Vaccine development for CCPP was attempted in India as early as 1950 (Verma, 2000). Few experimental attempts have been made for the development caprine pleuropneumonia vaccine for goats. These experimental vaccines against caprine pleuropneumonia have been evaluated from time to time (Srivastava et al., 1990; Singh 1990; Sikdar et al., 1993; Rana et al., 1999; Mehra et al., 2009) but its study on larger goat population is still required. At present there is no commercial vaccine available against major mycoplasmal diseases including caprine pleuropneumonia in India to combat morbidity and mortality losses in goats.

However the disease still persists in different states. Hence different measures were taken for improvement of small ruminants especially goats. There are many diseases affecting goats of which CCPP has gained importance in recent past due to its frequent occurrence and huge economic loss. Attempts were made from 1990s for the vaccine development against mycoplasma. Srivastava et al. (1990) conducted preliminary trials on attenuated vaccine against caprine pleuropneumonia. Sikdar et al. (1993) also conducted a preliminary investigation on development of a killed vaccine against caprine pleuropneumonia in goats. The lyophilized vaccine using Mycoplasma capricolum subsp. capripneumoniae was found to be effective in order to generate protective immunity against CCPP in goats in African countries as it was able to give protection of 12 months duration (Rurangirwa et al., 1987a; Rurangirwa et al., 1987b). Rana et al. (1999) studied humoral response in goats immunized with killed Mycoplasma mycoides subsp. capri saponin vaccine by slide agglutinatioin and latex agglutination tests. Kumar et al. (2009) studied immunogenicity of Mycoplasma agalactiae saponin vaccine in mice.

As mycoplasma are normal inhabitants of ovine and caprine respiratory tract and cause diseases only under stressful conditions like adverse climate, nutrient deficiency, overcrowding and immunosuppression hence better managemental interventions can be helpful for prophylactic regimes (Sheikh et al., 2008; Yatoo et al., 2014; Yatoo \& Kanwar, 2016).

\section{Treatment}

A wide range of antibiotics have been tried in therapeutic management of mycoplasmosis in sheep and goat under field conditions in India. They include oxytetracycline, enrofloxacin, tylosin, florfenicol, tiamulin and danofloxacin. Our field observations revealed several important findings regarding use of different antibiotics against mycoplasmosis under field conditions in Changthang. Oxytetracycline being the most commonly used and easily available antibiotic with good efficacy but results in abortion in pregnant animals and is generally in oily solvent hence highly painful besides intravenous administration is difficult due to both technical reasons and large herd size of small ruminants. Enrofloxacin though effective against mycoplasma under filed conditions and has good availability but concerns regarding fetal abnormalities (bone deformities) over prolonged use should be kept in mind. Tylosin is also highly effective under field conditions but it is usually not available under field conditions especially in remote and far-flung areas in India which are main areas for small ruminant farming.

Use of antibiotics in combination with anti-inflammatory, antipyretic, analgesic and anti-allergic drugs is not common under field conditions but is essential for preventing the pathogen induced severe inflammation, fever, thorax pain (pleurodynia) and allergic reactions. This will also minimize severity of disease and facilitate early recovery. However penicillins are found not effective against mycoplasma under field outbreaks which might be due to lack of cell wall. Many reports of use of antibiotics either alone or in combination with other drugs have been reported in several studies. Guha et al. (1985) studied effect of tylosin tartrate on experimental and natural cases of CCPP affected kids. Efficacy of oral administration of tylosin tartrate in the treatment of experimental and natural cases of caprine mycoplasmosis was noted by Bhaumik et al. (1990). Nayak \& Bhowmik (1990a) studied in vitro drug sensitivity and chemotherapy of mycoplasmal septicaemic polyarthritis in goat kids. Bagherwal \& Sisodia (1991) evaluated long acting oxytetracycline as chemotherapeutic agent against pneumonia in kids due to mycoplasma infection. Sarkar et al. (1992) studied treatment of natural cases of pneumonia associated with 
mycoplasma infection and found that the efficacy of treatment with tylosin was $66.67 \%$ and that of tiamulin $75 \%$. Bergonier et al. (1997) has reviewed some treatment aspects of contagious agalactia with Indian references. Kumar et al. (2012) studied antibiogram of Mycoplasma bovis in sheep pneumonia. Abraham et al. (2015) noted that the outbreak of CCPP was unresponsive to usual antibiotic therapy and was fast spreading within the flock. This may raise a concern about antibiotic resistance against mycoplasmosis due to prolonged use of antibiotics in different regions of various states in India. Similar observation we noted under field conditions wherein extensive of oxytetracycline may pose serious threat of antibiotic resistance against CCPP.

\section{Conclusion}

Mycoplasmosis has emerged as a recent and hidden threat to small ruminants in India causing huge economic and production losses. Frequent cases and outbreaks are noted in many states of the country but lack of proper diagnostic facilities renders reporting inefficient hence diagnosis is usually based on clinical presentation, postmortem and histopathological lesions. Mycoplasmosis in small ruminants involves a range of mycoplasma belonging to different species and subspecies. Common ones are Mycoplasma capri subsp capripneumonia (goats), M. agalactiae (goats and sheep), M. ovipneumoniae (sheep), M. mycoides subsp. mycoides (cattle), M. mycoides subsp. capri (goats), M. putrefaciens (goats), M. conjunctivae (sheep), M. capricolum (goats), M. arginini (all ruminants). Despite difficulties in diagnosis focus should be on devising good and skilled technical expertise, laboratory infrastructure and funding for proper diagnostic facilities with particular focus on both conventional diagnostics including cultural, biochemical, microbiological testing and advanced molecular techniques including serological like CFT, LFA, ELISA, agglutination and gene and protein based techniques viz. PCR, RFLP, sequencing, microaaray, SDS-PAGE, and western blot. Though commercial vaccines are yet to be available against most of the pathogenic and frequently occurring mycoplasmal diseases occurring in different states of the country, by that time development on novel curative regimes should be parallel focused upon. The development of vaccines using local isolates should be given more emphasis. This may be conferring immunity of longer duration as well as to all the age group of animals. Therapeutics involving antibiotics for prolonged time should be regulated with evaluation of efficacy of antibiotics against mycoplasmosis in particular areas so as to minimize unnecessary costs and risk of antibiotic resistance.

\section{Acknowledgment}

All authors acknowledge their respective Universities/Institutes. This study is supported by Science and Engineering Board (SERB), Department of Science and Technology (DST), Govt. of India under project EMR/2016/004929. Financial assistance by
SERB-DST under project EMR/2016/004929 is highly acknowledged.

\section{Conflict of interest}

Authors would hereby like to declare that there is no conflict of interests that could possibly arise.

\section{References}

Abraham SS, Asha TT, Julie B, Prathiush PR, Nandakumar S, Prasad PM (2015) Pathological and molecular characterization of contagious caprine pleuropneumonia (CCPP) outbreak in Kerala. Indian Journal of Veterinary Pathology 39: 121-124.

Al-Aubaidi JM (1972) Biochemical characterization and serological classification of caprine and ovine mycoplasma with special reference to the antigenic relationships of M. mycoides var. capri and M. mycoides var. mycoides. $\mathrm{PhD}$ thesis submitted to the Cornell University.

Ambroset C, Pau-Roblot C, Game Y, Gaurivaud P, Tardy F (2017) Identification and characterization of Mycoplasma feriruminatoris sp. nov. Strains isolated from Alpine Ibex: A $4^{\text {th }}$ species in the Mycoplasma mycoides cluster hosted by nondomesticated ruminants? Frontiers in Microbiology 8: 939.

Amores J, Sánchez A, Gómez-Martín A, Corrales JC, Contreras A, de la Fe C (2012) Surveillance of Mycoplasma agalactiae and Mycoplasma mycoides subsp. capri in dairy goat herds. Small Ruminant Research 102: 89-93.

Arun TR, Rana R, Singh P, Choudhuri P, Singh VP, Thomas P, Rekha V, Nehra K, Usharani J, Dhama K (2014) Development of a gold nanoparticle based lateral flow assay for rapid diagnosis of contagious agalactia in goats. Asian Journal of Animal and Veterinary Advances 9: 405-413.

Awan MA, Abbas F, Yasinzai M, Nicholas R, Babar S, Ayling RD, Attique MA, Ahmed Z (2009) Prevalence of Mycoplasma capricolum subspecies capricolum and Mycoplasma putrefaciens in goats in Pishin district of Balochistan. Pakistan Veterinary Journal 29: 179- 185.

Awan MA, Abbas F, Yasinzai M, Nicholas RA, Babar S, Ayling RD, Attique MA, Ahmed Z, Wadood A, Khan FA (2010) First report on the molecular prevalence of Mycoplasma capricolum subspecies capripneumoniae (Mccp) in goats the cause of contagious caprine pleuropneumonia (CCPP) in Balochistan province of Pakistan. Molecular Biology Reports 37 : 3401-3406.

Awati B, Chavhan SK (2013) Seroprevalence of Contagious Caprine Pleuropneumonia in Small Ruminants in North Karnataka. Indian Veterinary Journal 90: 123. 
Bagherwal RK, Sisodia RS (1991) Long acting oxytetracycline as chemotherapeutic agent against pneumonia in kids due to mycoplasma infection. Indian Journal of Veterinary Medicine 15 : 140-141.

Barbuddhe SB, Sundaram RNS, Chakurkar EB, Sahare AM, Swain BK (2005) Seroprevalence of contagious caprine pleuropneumonia, bluetongue and peste des petits ruminants among goats in Goa region. Indian Jornal of Comparative Microbiology, Immunology and Infectious Diseases 26: 42-43.

Bawa HS (1944) Some observations on "Wah" of goats and sheep in Shind. Indian Journal of Veterinary Sciences 14: 105-110.

Bergonier D, Berthelot X, Poumarat F (1997) Contagious agalactia of small ruminants: current knowledge concerning epidemiology, diagnosis and control. Review Scientific Technique Office International Epizootie $16: 848-873$

Bhaumik A, Verma BB, Thakur DK, Pandey SN, Banerjee NC (1990) Effect of oral administration of tylosin tartrate in the treatment of experimental and natural cases of caprine mycoplasmosis. Indian Veterinary Journal 67: 948-951.

Chakraborty S, Kumar A, Tiwari R, Rahal A, Malik Y, Dhama K, Pal A, Prasad M (2014) Advances in diagnosis of respiratory diseases of small ruminants. Veterinary Medicine International 2014: 508304. DOI: http://dx.doi.org/10.1155/2014/508304.

Chu Y, Gao P, Zhao P, He Y, Liao N, Jackman S, Zhao Y, Birol I, Duan X, Lu Z (2011) Genome sequence of Mycoplasma capricolum subsp. capripneumoniae strain M1601. Journal of Bacteriology 193: 6098-6099.

Cottew GS, Yeats FR (1978) Subdivision of M. mycoides subsp. mycoides from cattle and goats into two types. Australian Veterinary Journal 54: 293-296.

DaMassa Al J, Wakenell PS, Dale L (1992) Brooks Mycoplasmas of goats and sheep. Journal of Veterinary Diagnostic Investigation 4: 101-113.

DaMassa AJ (1996) Mycoplasma infections of goats and sheep. In: Tully JG, Razin S (Eds.) Molecular and diagnostic procedures in mycoplasmology. Vol II. Academic Press, San Diego, 265-273.

Darzi MM, Sood N, Gupta PP, Banga HS (1998) The pathogenicity and pathogenesis of Mycoplasma capricolum subsp. capripneumoniae (F38) in the caprine mammary gland. Veterinary Research Communications 22:155-165.

Dinesh CN, Sonawane A, Kumar A, Rana R, Chauhan A, Sharma D (2013) Effect of genetic and non-genetic factors on seroprevalance of Mycoplasma mycoides subsp. capri in goat. Journal of Veterinary and Animal Science 44: 38-41.
Dupuy V, Verdier A, Thiaucourt F, Manso-Silvan L (2015) A large scale genomic approach affords unprecedented resolution for the molecular epidemiology and evolutionary history of contagious caprine pleuropneumonia. Veterinary Research 46: 74.

Erno H, Leach RH, Salih MM, MacOwan KJ (1983) The F38-like group, a new group of caprine mycoplasmas? Acta Veterinaria Scandinavica 24: 275-286.

Ghosh SS, Srivastava NC, Sikdar A, Gupta BR (1989) Seroprevalence of caprine mycoplasma in Tripura. Indian Veterinary Journal 66: 577-579.

Gonçalves R, Mariano I, Núñez A, Branco S, Fairfoul G, Nicholas $\mathrm{R}$ (2010) Atypical non-progressive pneumonia in goats. Veterinary Journal 183: 219-221.

Guha C, Verma BB, Deb AR (1985) Treatment of experimental and natural cases of contagious caprine pleuropneumonia in kids with tylosin tartrate (Tylan-50). Indian Veterinary Journal 62 : 310-312.

Gupta DK, Shukla PC, Tiwari A, Baghel RPS, Sharma V, Shivhare J, Gupta N (2016) Seroprevalence study on goat contagious caprine pleuropneumonia in Jabalpur, Madhya Pradesh. Journal of Animal Research 6: 743-746.

Gupta MM, Verma BR, Chauhan HVS (1984) Contagious caprine pleuropneumonia: studies on etiopathology. Indian Veterinary Journal 61: 733-737.

Gupta S, Chahota R, Bhardwaj B, Malik P, Verma S, Sharma M (2015) Identification of chlamydiae and mycoplasma species in ruminants with ocular infections. Letters in Applied Microbiology 60: 135-139.

Hussain R, Auon M, Khan A, Khan MZ, Mahmood F, UrRehman S (2012) Caprine pleuropneumonia in Beetal goats. Tropical Animal Health Production 44: 477-81.

Ingle VC, Sivakumar P, Kalorey DR, Pote DE, Patil D, Chavan PS, Nagadive AA, Hatkar DN (2008) Seroprevalence of contagious caprine pleuropneumonia in goats in Nagpur district of Vidarbha region. Veterinary World 9: 270-271.

IVRI (2016) Annual Report, 2015-16. M/s Anoopam Press, Bareilly.

Jain U, Verma AK, Pal BC (2015) Occurrence of mycoplasma infection in Barbari goats of Uttar Pradesh, India. Haryana Veterinarian $54:$ 53-55.

Jana C, Bhowmik MK, Sadhukhan T (2005) Mycoplasmal pneumonia in garole sheep. Veterinarski Arhiv 75 : 183-188. 
Jones GE, Wood AR (1988) Microbiological and serological studies on caprine pneumonias in Oman. Research Veterinary Science 44: 125-31.

Kashoo ZA, Singh VP, Rana R, Singh R, Chandra S, Sankar M (2013) Cloning of p80 gene in Indian isolates of Mycoplasma agalactiae. Indian Journal of Small Ruminants 19: 167-171.

Kibor AC, Waiyaki PG (1986) Growth of mycoplasma F38 in medium B (modified Hayflick) and Newinges typtose medium. Bulletin Animal Health Production Africa 34: 157-159.

Kizil O, Ozdemir H (2006) Clinical, haematological and biochemical studies in goats naturally infected with Mycoplasma agalactiae. Bulletin of the Veterinary Institute in Pulawy 50 : 325-328.

Kumar A, Chandiramani NK (1987) Isolation and characterization of $M$. agalactiae from premature born kids of goats. Indian Journal of Comparative Microbiology, Immunology and Infectious Diseases 8: 95-97.

Kumar A, Garg DN (1991) Isolation of Mycoplasma F-38 from the milk of mastitic cows. Veterinary Record 128: 429.

Kumar A, Rahal A, Chakraborty S, Verma AK, Dhama K (2014) Mycoplasma agalactiae, an etiological agent of Contagious agalactia in small ruminants: A review. Veterinary Medicine International e286752.

Kumar A, Srivastava NC, Singh VP (2009) Immunogenicity of Mycoplasma agalactiae saponin vaccine in mice. Indian Journal of Comparative Microbiology, Immunology and Infectious Diseases 30: 61-62.

Kumar A, Srivastava NC, Singh VP (2010) Pathogenicity of Mycoplasma agalactiae in mice. Indian Journal of Small Ruminant 16: 269-270.

Kumar A, Srivastava NC, Singh VP (2002) Rapid identification of $M$. agalactiae and M. bovis by immuno binding assay. Indian Journal of Comparative Microbiology, Immunology and Infectious Diseases 23: 161-163.

Kumar A, Verma AK, Gangwar NK, Rahal A (2012) Isolation, characterization and antibiogram of Mycoplasma bovis in sheep pneumonia. Asian Journal of Animal and Veterinary Advances 7: 149-157.

Kumar P, Roy A, Bhanderi BB, Pal BC (2011a) Isolation, identification and molecular characterization of Mycoplasma isolates from goats of Gujarat State, India. Veterinarski Arhiv 81: 443-458,.
Kumar A, Verma AK, Rahal A (2011b) Mycoplasma bovis, a multi disease producing pathogen: an overview. Asian Journal of Animal and Veterinary Advances 6: 537-546.

Kumar M, Singh VP, Srivastava NC (2001) Rapid and specific detection of M. mycoides cluster and differentiation of mycoides group from capricolum group by PCR. Indian Journal of Comparative Microbiology, Immunology and Infectious Diseases 22: $118-121$,

Kumar V, Rana R, Mehra S, Rout PK (2013) Isolation and characterization of Mycoplasma mycoides subspecies capri from milk of natural goat mastitis cases. ISRN Veterinary Science 2013: 593029.

Kusiluka LJ, Semuguruka WD, Kazwala RR, Ojeniy B, Friis NF (2000) Demonstration of Mycoplasma capricolum subsp. capripneumoniae and Mycoplasma mycoides subsp. mycoides, small colony type in outbreaks of caprine pleuropneumonia in eastern Tanzania. Acta Veterinary Scandinavia 41: 311-319.

Lambert M (1987) Contagious agalactia of sheep and goats. Revue Scientifique et Technique. Office International des Epizooties 6: 699-711.

Leach RH (1967) Comparative studies of Mycoplasma of bovine origin. Annals New York Academy of Science 143: 305-316.

Liljander A, Yu M, O'Brien E, Heller M, Nepper JF, Weibel DB, Gluecks I, Younan M, Frey J, Falquet L, Jores J (2015) Fieldapplicable recombinase polymerase amplification assay for rapid detection of Mycoplasma capricolum subsp. capripneumoniae. Journal of Clinical Microbiology 53 : 2810-2815.

MacOwan KJ, Minette JE (1976) A mycoplasma from acute contagious caprine pleuropneumonia in Kenya. Tropical Animal Health Production 8: 91-95.

Madanat M, Zendulkova D, Pospisil Z (2001) Contagious agalactia of sheep and goats. A review. Acta Veterinaria Brno 70: 403-412.

Manso-Silvan L, Vilei EM, Sachse K, Djordjevic SP, Thiaucourt F, Frey J (2009) Mycoplasma leachii sp. nov. as a new species designation for Mycoplasma sp. Bovine group 7 of Leach, and reclassification of Mycoplasma mycoides subsp. mycoides LC as a serovar of Mycoplasma mycoides subsp. capri. International Journal Systemic Evolution Microbiology 59: 1353-1358.

Manso-Silvan L, Dupuy V, Chu Y, Thiaucourt F (2011) Multilocus sequence analysis of Mycoplasma capricolum subsp. capripneumoniae for the molecular epidemiology of contagious caprine pleuropneumonia. Veterinary Research 42: 86. 
Maru A, Srivastava CP, Dubey SC, Lonkar PS (1990) Epidemiology of pneumonia in sheep flocks. Annual Report. CSWRI, Avikanagar, India. Pp. 53.

Mehra S, Rana R, Mondal nA, Kumar V, Kumar A, Vihan VS, Sharma MC (2009). Comparative evaluation of antibody response in goats vaccinated with Saponin and Saponin-Algel Mycoplasma mycoides subsp. capri vaccines by Enzyme Linked Immunosorbant Assay. Indian Journal of Animal Sciences. 79: 1127-1129

Misri J, Gupta PP, Sood N (1988). Experimental Mycoplasma capri mastitis in goats. Australian Veterinary Journal 65: 33-35.

Mohan K, Miles RJ, Wadher BJ (1990) Growth and biochemical characteristics of mycoplasmas isolated from the lungs of Nigerian goats. Zentralblatt Fur Bakteriologie 20: 841-843.

Mohan K, Obwolo MJ (1990) Mycoplasma ovipneumoniae pathogenesis in experimentally infected sheep and goats. IOM Letters, Program and Abstracts, 8th International Congress IOM, July 8- 12, Istanbul, Turkey, 1:355-356.

Mondal D, Pramanik AK, Basak DK (2004) Clinico- haematology and pathology of caprine mycoplasma pneumonia in rain fed tropics of West Bengal. Small Ruminant Research 51: 285-295.

Nayak NC, Bhowmik MK (1990a) In vitro drug sensitivity and chemotherapy of mycoplasmal septicaemic polyarthritis in goat kids. Indian Journal of Animal Science 60: 557-559.

Nayak NC, Bhowmik MK (1990b) Mycoplasmal septicaemic polyarthritis in goat kids: epizootiological studies. Indian Journal of Veterinary Medicine 14: 43-46.

Nicholas R, Ayling R, McAuliffe L (2008) Mycoplasma Diseases of Ruminants. CABI, Pp 117.

Nicholas R, Ayling R, McAuliffe L (2009) Mycoplasma Diseases of Ruminants, Disease, Diagnosis and Control. Pp 256.

Nicholas RAJ (2002) Improvements in the diagnosis and control of diseases of small ruminants caused by mycoplasmas. Small Ruminant Research 45: 145-49.

Nicolet J (1996) Animal mycoplasmoses: a general introduction. Scientific and Technical Review of the Office International des Epizooties (Paris) 15: 1233-1240.

OIE (2009) World Animal Health Information Database Version: 1.4. World Animal Health Information Database. Paris, France: World Organisation for Animal Health. http://www.oie.int
OIE (2017a) OIE Terristerial Manual 2017. OIE Manual of Diagnostic Tests and Vaccines for Terrestrial Animals seventh Edition, 2012. Volumes 1 and 2, pp 1404.

OIE (2017b) OIE - Terrestrial Animal Health Code Twenty-sixth edition, 2017. World Organisation For Animal Health 12, rue de Prony, 75017 Paris, FRANCE

Pettersson B, Leitner T, Ronaghi M, Bolske G, Uhlen M, Johansson KE (1996) Phylogeny of the Mycoplasma mycoides cluster as determined by sequence analysis of the $16 \mathrm{~S}$ rRNA genes from the two rRNA operons. Journal of Bacteriology 178: 4131-4142.

Peyraud A, Poumarat F, Tardy F, Manso-Silván L, Hamroev K, Tilloev T, Amirbekov M, Tounkara K, Bodjo C, Wesonga H, Nkando IG, Jenberie S, Yami M, Cardinale E, Meenowa D, Jaumally MR, Yaqub T, Shabbir MZ, Mukhtar N, Halimi M, Ziay GM, Schauwers W, Noori H, Rajabi AM, Ostrowski S, Thiaucourt F (2014) An international collaborative study to determine the prevalence of contagious caprine pleuropneumonia by monoclonal antibody-based cELISA. BMC Veterinary Research 10: 48. doi: 10.1186/1746-6148-10-48.

Priya PM, Baburaj NK, Kiran N, Rajan S, Ravishankar C, Jayesh $\mathrm{V}$ (2008) A cross sectional investigation on CCPP among goats of Wayanad district of Kerala, India. Bioscience Biotechnology Research Communications 1: 140-142.

Pradhan RK (1997) Sheep and goat disease problem in humid region.Comp., Third National Seminar on Small Ruminant Disease, 2-3 December, 2007 at CIRG, Makhdoom, Mathura (U.P.) pp 29-34.

Prats-van der Ham M, Christiande la Fe, Amores J, Paterna A, Tatay-Dualde J, Gómez-Martín A (2015) Contagious caprine pleuropneumonia (CCPP) and other emergent mycoplasmal diseases affecting small ruminants in arid lands. Journal of Arid Environments 119: 9-15.

Prats-van der Ham M, Tatay-Dualde J, de la Fe C, Paterna A, Sánchez A, Corrales JC, Contreras A, Gómez-Martín Á (2017) Molecular resistance mechanisms of Mycoplasma agalactiae to macrolides and lincomycin. Veterinary Microbiology 211: 135140.

Rahal A, Ahmad AH, Prakash A, Mandil R, Kumar AT (2014) Environmental attributes to respiratory diseases of small ruminants. Veterinary Medicine International 2014: 10 pages. DOI: http://dx.doi.org/10.1155/2014/853627. 
Ramdeva J, Sharma M, Katoch VC, Dhar P, Chahota R(2008) Seroprevalence of Mycoplasmosis in sheep and goats of H.P. Indian Journal of small Ruminants 14: 32-34.

Rana R, Srivastava NC, Singh VP (1999) Monitoring of humoral response in goats immunized with killed Mycoplasma mycoides subsp. capri saponin vaccine by slide agglutinatioin and latex agglutination tests. Indian Journal of Comparative Microbiology Immunology and Infectious Diseases 20: 39-41

Ravishankar C, Priya PM, Ravindran R, Ajithkumar S (2011) Outbreak of mycoplasmosis in an organised goat farm in Kannur district of Kerala. Journal of Veterinary and Animal Science 42: 66-67.

Razin S, Yogev D, Naot Y (1998) Molecular biology and pathogenicity of mycoplasmas. Microbiology Molecular Biology Reviews 62 : 1094-156.

Razin S, Tully JG (eds) (1995) Molecular and diagnostic procedures in mycoplasmology. Vol. I. Molecular characterization. Academic Press, San Diego, California, 483 pp. 5.

Real F, Deniz S, Acosta B, Ferrer O, Poveda JB (1994) Caprine contagious agalactia caused by Mycoplasma agalactiae in the Canary Islands. Veterinary Record 135: 15-16.

Rekha V, Rana R, Arun TR, Awasthi PB, John JK, Gopinath D, Sadanandan GV, Jacob A (2014) Loop mediated Isothermal Amplification (LAMP) test - a novel nucleic acid based assay for the disease diagnosis. Advances in Animal and Veterinary Sciences 2: 344-350.

Rekha V, Rana R, Remesh AT, Singh VP (2017) Mycoplasma arginini: high frequency involvement in goat pneumonia. Turkish Journal of Veterinary \& Animal Sciences 41: 393-399.

Rekha V, Rana R, Thomas P, Viswas KN, Singh VP, Agarwal RK, Arun TR, Karthik K, Sophia I (2015) Development of loopmediated isothermal amplification test for the diagnosis of contagious agalactia in goats. Tropical Animal Health and Production 47: 581-587.

Rifatbegović M, Maksimović Z, Hulaj B (2011) Mycoplasma ovipneumoniae associated with severe respiratory disease in goats. Veterinary Record 168: 565.

Roy A, Kumar P, Bhanderi BB (2010) Detection of Mycoplasma capri antibodies in goats of Gujarat state. Veterinary World 3: 471-472.

Ruffin DC (2001) Mycoplasma infections in small ruminants. Veterinary Clinical North American Food Animal Practice 17: 315-32.
Rurangirwa FR, McGuire TC (1996) Contagious caprine pleuropneumonia: Diagnosis and control. In: Lebbie S.H.B. and Kagwini E. 1996. Small Ruminant Research and Development in Africa. Proceedings of the Third Biennial Conference of the African Small Ruminant Research Network, UICC, Kampala, Uganda, 5-9 December 1994. ILRI (International Livestock Research Institute) Nairobi, Kenya. 326 pp.

Rurangirwa FR, McGuire TC, Chema S, Kibor A (1987a) Vaccination against contagious caprine pleuropneumonia caused by F38. Israel Journal of Medical Sciences 23: 641-643.

Rurangirwa FR, McGuire TC, Musoke AJ, Kibor A (1987b) Differentiation of F38 mycoplasmas causing contagious caprine pleuropneumonia with a growth inhibiting monoclonal antibody. Infection and Immunity 55: 3219-3220.

Sadique U, Chaudhry ZI, Younus M, Anjum AA, Idrees M, Qureshi MS, Sajid A, Hassan ZU, Mushtaq M, Subtain SM (2012) Clinico-pathological study of contagious caprine pleuropneumonia (CCPP) in small ruminants. The Journal of Animal and Plant Sciences 22: 45-50.

Saminathan M, Rana R, Ramakrishnan MA, Karthik K, Malik YS, Dhama K (2016) Prevalence, diagnosis, management and control of important diseases of ruminants with special reference to Indian scenario. Journal of Experimental Biology and Agricultural Sciences $4: 338-367$.

Samiullah S (2013) Contagious caprine pleuropneumonia and its current picture in Pakistan: A review. Veterinarni Medicina 8: 389-398.

Sarkar AK, Verma BB, Thakur DK (1992) Treatment of natural cases of pneumonia associated with mycoplasma infection. Indian Veterinary Journal 69: 1041-1042.

Settypalli TBK, Lamien CE, Spergser J, Lelenta M, Wade A, Gelaye E, Loitsch A, Minoungou G, Thiaucourt F, Diallo A (2016) One-Step Multiplex RT-qPCR Assay for the detection of Peste des petits ruminants virus, Capripoxvirus, Pasteurella multocida and Mycoplasma capricolum subspecies (ssp.) capripneumoniae. PLoS ONE 11: e0153688.

Shaheen M, Haque S, Thakur DK (2001) Contagious caprine pleuropneumonia in kids in Ranchi. Indian Journal of Animal Science 71:136-138.

Shahzad W, Munir R, Rana MY, Ahmad R, Khan MS, Akbar G, Ijaz M, Mehmood F (2013) Prevalence, molecular diagnosis and treatment of Mycoplasma conjunctivae isolated from infectious keratoconjunctivitis affected Lohi sheep maintained at Livestock 
Experiment Station, Bahadurnagar, Okara, Pakistan. Tropical Animal Health and Production 45: 737-742.

Sheikh FD, Wani SA, Fatima K, Masoodi TH (2016) Contagios caprine pleuropneumonia: A major threat to pashmina farimg in Ladakh. High Mountain Arid Agricultural Research Institute (HMAARI) pamphlet. Pp 1-8.

Sheikh FD, Azmat S, Ganai TAS, Misrai SS, Azmat S (2008) Socio-economic role of Pashmina goats in Changthang region. Indian Journal of Animal Science 78 : 1298-1301.

Sikdar A, Sirvastava NC, Uppal PK (1993) Development of a killed vaccine against caprine pleuropneumonia: preliminary investigation in goats. Indian Veterinary Journal 70: 600-604.

Singh N, Rajya BS, Mohanty GC (1974) Granular vulvovaginitis (GW) in goats associated with Mycoplasma agalactiae. Cornell Veterinarian 64: 435-442.

Singh, VP (1990) Immunogenicity of plasma membrane, protein fraction and sonicated suspension of Mycoplasma mycoides subsp. capri in goats, rabbits and mice. Ph.D. thesis submitted to IVRI, Deemed University, Izatnagar, U.P., India

Singh, VP, Srivastava NC,. Kumar M, Sunder M, Varshney JPJ (2004) Isolation and characterisation of an Indian strain of Mycoplasma mycoides subsp. mycoides type LC from a case of caprine arthritis. Comparative Immunology, Microbiology and Infectious Diseases 27: 273- 284.

Srivastava NC, Sikdar A, Srivastava SK (1990) Preliminary trials on the development of an attenuated vaccine against caprine pleuropneumonia. Indian Journal of Animal Science 60: 645-647.

Srivastava NC, Singh VP (2000) Annual Report, Division of Bacteriology and Mycology, IVRI, Izatnagar, India.

Srivastava NC, Thiaucourt F, Singh VP, Sunder J, Singh VP (2000) Isolation of Mycoplasma mycoides small colony type from contagious caprine pleuropneumonia in India. Veterinary Record 147: 520-521.

Suryawanshi SN, Tembhurne PA, Gohain S, Kesharkar JA, Tumlam UM, Ingle VC (2015) Seroprevalence of contagious caprine pleuropneumonia in small ruminants in Maharastra. The Indian Journal of Veterinary Science and Biotechnology 10: 7374.

Tatay-Dualde J, Prats-van der Ham M, de la Fe C, Gómez-Martín Á, Paterna A, Corrales JC, Contreras A, Sánchez A (2016) Multilocus sequence typing of Mycoplasma mycoides subsp. capri to assess its genetic variability in a contagious agalactia endemic area. Veterinary Microbiology191: 60-64.
Tatay-Dualde J, Prats-van der Ham M, de la Fe C, Paterna A, Sánchez A, Corrales JC, Contreras A, Gómez-Martín Á (2017) Mutations in the quinolone resistance determining region conferring resistance to fluoroquinolones in Mycoplasma agalactiae. Veterinary Microbiology 207: 63-68.

Tatay-Dualde J, Sánchez A, Prats-van der Ham M, Gómez-Martín A, Paterna A, Corrales JC, de la Fe C, Contreras A, Amores J (2015) Sensitivity of two methods to detect Mycoplasma agalactiae in goat milk. Irish Veterinary Journal 68: 21.

Thankappan S, Rana R, Remesh AT, Rekha V, Nagaleekar VK, Puvvala B (2017) Cloning and expression of P67 protein of Mycoplasma leachii. Veterinary World 10: 1108-1113.

Thiaucourt F, Bolske G (1996) Contagious caprine pleuropneumonia and other pulmonary mycoplasmosis of sheep and goats. Review Scientific Technique Office International Epizootie 15: 1397-1414.

Thiaucourt F, Guerin C, Mady V, Lefevre PC (1992) Diagnostic de la pleuropneumonie contagieuse caprine: améliorations récentes. Review Scientific Techniques Office International Epizootie11: 859-865.

Tigga M, Choudhary BK, Ghosh RC, Malik P (2014) Mycoplasmosis: An emerging threat to developing livestock industry. International Journal of Advanced Research 2: 558-564.

Tiwari A, Shukla PC, Gupta DK, Baghel RPS, Sharma V, Shivhare J (2015) Seroprevalence of contagious agalactia in goats. International Journal of Current Research 7: 24760-24762.

Tully JG, Razin S (eds) (1996) Molecular and diagnostic procedures in mycoplasmology. Vol. II. Diagnostic procedures. Academic Press, San Diego, California, Pp. 466.

Udit J, Chand BP (2008) Epidemiology of Mycoplasma pneumonia in goats of India. International Organization for Mycoplasmology. 17th International Congress. July 6-11, 2008, Tianjin Medical University, China. Pp 67.

Verma R (2000) Glimpses of Indian Veterinary Science, Daya Publishing House Delhi.

Walker GK (1914) Pleuro-pneumonia of goats in the Kangra district, Punjab. Indian Journal of Comparative Pathology Therapeutics 27: 68-71.

Woubit S, Lorenzon S, Peyraud A, Manso-Silván L, Thiaucourt F (2004) A specific PCR for the identification of Mycoplasma capricolum subsp. capripneumoniae, the causative agent of contagious caprine pleuropneumonia (CCPP). Veterinary Microbiology 104 : 125-132. 
Yu Z, Wang T, Sun H, Xia Z, Zhang K, Chu D (2013) Contagious caprine pleuropneumonia in endangered Tibetan antelope, China, 2012. Emerging Infectious Diseases 19: 2051-2053.

Yatoo MI, Kanwar MS, Kubrevi SS, Shabir M, Dar R, Angmo K (2014) Safeguarding a national asset: a review on problems faced by pashmina farmers in Changthang and their amelioration. Indian
Journal of Animal Science 84: 1251-1255.

Yatoo MI, Kanwar MS (2016) Management of common diseases of livestock in Changthang. Krishi Vigyan Kendra (KVK) Nyoma pamphlet. 1-16.

Young L, Sung J, Stacey G, Masters JR (2010) Detection of Mycoplasma in cell cultures. Nature Protocols 5: 929-934. 